\title{
I-(I-hydroxynaphthalen-2-YI) ethanone: crystal structure, photo physical study and turn off molecular switch with cu (ii) ion
}

\begin{abstract}
A simple 1-naphthol derivative, 1-(1-hydroxynaphthalen-2-yl) ethanone (1-NAPH) was used for selective detection of $\mathrm{Cu}^{2+}$ ions and the $\mathrm{X}$-ray single-crystal structure was reported. The structure is stabilized by intramolecular H-bonding and by intermolecular $\mathrm{C}-\mathrm{H} \bullet \bullet \pi$ and $\pi-\pi$ stacking interactions. Study of the photo physical behavior of naphthol derivative towards $\mathrm{Cu}^{2+}$ ion was explored in methanol medium. When titrated with various metal ions, the fluorescence emission of 1-NAPH was quenched in the presence of $\mathrm{Cu}^{2+}$ ion. Hence, 1-NAPH acts as a molecular switch towards $\mathrm{Cu}^{2+}$ ions due to its fluorescence turn "OFF" behavior.
\end{abstract}

Keywords: naphthol, crystal structure, $\mathrm{cu}^{2+}$ detection, fluorescence quenching, molecular switch

\author{
Volume I Issue 4 - 2017 \\ G Tamil Selvan,' V Chitra,' IVMV Enoch,' \\ Paulraj Mosae Selvakumar,' E Suresh ${ }^{2}$ \\ 'Department of Chemistry, Karunya University, India \\ ${ }^{2}$ Analytical Science discipline, CSMCRI (CSIR), India
}

Correspondence: Paulraj Mosae Selvakumar, Department of Chemistry, Karunya University, Coimbatore, Tamilnadu, India-64 I I 14,Email pmosae@gmail.com

Received: August 22, 2017 | Published: September 20, 2017

\section{Introduction}

Detection of metal cations has received special attention since they play important role in the living system. To detect and control metal ions in aqueous solution is also very important. Among the various transition metal ions, copper (II) ion is a significant environmental pollutant depending on its concentration while it is an essential trace element in biological systems. ${ }^{1}$ Deficiency of copper leads to Menkes disease, but high levels can cause Alzheimer ${ }^{2}$ or Parkinson's disease ${ }^{3}$ and kidney damage. $\mathrm{Cu}^{2+}$ ion can be detected using various instrumental techniques. However, most of the methods are timeconsuming and requires expensive instrumentation techniques. ${ }^{4-9}$ Therefore, development of a selective, sensitive and easy method ${ }^{10-14}$ to detect $\mathrm{Cu}^{2+}$ ions becomes essential. $\mathrm{Cu}^{2+}$ ion is a fluorescent quencher due to its paramagnetic nature and so a fluorescent receptor responds towards $\mathrm{Cu}^{2+}$ ion can act as molecular switches. ${ }^{15-17}$

Naphthaldehyde, hydroxy-naphthaldehyde and their derivatives are an important class of intermediates which condenses with primary amines to afford Schiff bases that are one of most versatile mixeddonor ligands in the field of coordination chemistry. In this paper, we have reported1-(1-hydroxynaphthalen-2-yl) ethanone, 1-NAPH and its photophysical studies for the detection of $\mathrm{Cu}^{2+}$ ions in aqueous medium. 1-NAPH acts as on-off-on molecular switch towards $\mathrm{Cu}^{2+}$ ions due to its fluorescence Turn "OFF" behavior. The crystal structure of the receptor and its molecular switch behavior with $\mathrm{Cu}^{2+}$ ion was also explored.

\section{Materials and methods}

\section{Reagents}

All reagents and chemicals, unless stated otherwise, were purchased from commercial suppliers and used without further purification. 1-Hydroxy-2-acetonaphthone was purchased from Aldrich. All inorganic salts used were of analytical grade. Thrice distilled water was used throughout the experiments. Ortho phosphoric acid buffer solutions were prepared and used for $\mathrm{pH}$ studies.

\section{Instrumentation}

UV-Visible and fluorescence spectral studies were recorded using a double-beam Jasco V630 spectrophotometer and a Jasco FP-8300 spectrofluorometer respectively using cuvettes of $1.0 \mathrm{~cm}$ path length. The spectrofluorometer used a 120W Xenon lamp as the excitation source and the excitation and emission bandwidths were fixed at $5.0 \mathrm{~nm}$. A crystal of suitable size was selected and mounted on the tip of a glass fiber and cemented using epoxy resin Intensity data for crystal were collected using Mo-K $\alpha(\lambda=0.71073 \AA)$ radiation on a Bruker SMART APEX diffractometers equipped with CCD area detector at $100 \mathrm{~K}$. An empirical absorption correction was applied to the collected reflections with SADABS..$^{18}$ The structures were solved by direct methods using SHELXTL ${ }^{19}$ and were refined on F2 by the full-matrix least-squares method using the SHELXL- $97^{20}$ package. Graphics are generated using PLATON ${ }^{21}$ and MERCURY 1.3. ${ }^{22}$ All non-hydrogen atoms were refined anisotropically till convergence is reached. Hydrogen atoms in the compound were fixed at idealized positions stereochemically.

\section{Preparation of single crystal}

1-Hydroxy-2-acetonaphthone was crystallized in methanol solution. Pale-yellow needle-like single crystals suitable for X-ray diffraction studies were obtained after several weeks by slow evaporation from methanol-ethyl ether (1:3) mixed solution.

\section{UV-Visible and fluorescence spectroscopic studies}

Standard stock solution of 1-NAPH $\left(1 \times 10^{-3} \mathrm{M}\right)$ was prepared in methanol. Various metal ion solution $\left(1 \times 10^{-3} \mathrm{M}\right)$ viz., $\mathrm{Eu}^{3+}, \mathrm{Pb}^{2+}, \mathrm{Cu}^{2+}$, $\mathrm{Ni}^{2+}, \mathrm{Cd}^{2+}, \mathrm{Na}^{+}, \mathrm{Ca}^{2+}, \mathrm{Mn}^{2+}, \mathrm{Ba}^{2+}, \mathrm{Mg}^{2+}, \mathrm{NH}^{4+}, \mathrm{Li}^{+}, \mathrm{Al}^{3+}, \mathrm{Hg}^{2+}, \mathrm{K}^{+}, \mathrm{Fe}^{2+}$ and $\mathrm{Zn}^{2+}$ were prepared by dissolving the exactly weighed amount of the metal salts in standard measuring flask. Working solutions were prepared by diluting the stock solutions. The spectrum was recorded by adding various metal ion solution to 1 -NAPH. Standard measuring flasks containing the test solutions were thoroughly mixed for few minutes at room temperature before recording UV-Vis and fluorescent spectra. 


\section{Preparation of various $\mathrm{pH}$ solutions}

Solutions of various $\mathrm{pH} 2,3,4,5,6,7,8,9,10,11,12$ were prepared by mixing appropriate amounts of orthophosphoric acid and $\mathrm{NaOH}$. Solutions of 1-NAPH and $\mathrm{Cu}^{2+}$ were diluted in various $\mathrm{pH}$ solutions $\mathrm{pH}$ 2.0-12.0 and its UV-Visible and Fluorescence spectra were recorded. All pH values were measured with Elico $2 \mathrm{~F} 120$ (India) $\mathrm{pH}$ meter.

\section{Results and discussion}

\section{Single crystal structure}

Suitable single crystal for compound 1-NAPH was obtained upon slow evaporation at room temperature in a week. Compound 1-NAPH crystallizes in Space group P 21/n(a=7.4808(12), b=6.9867(11), $\mathrm{c}=17.450(3))$. The ORTEP view of the compound1-NAPH is depicted in Figure 1. X-Ray crystallographic analysis revealed the role of intermolecular hydrogen bonding in the compound and the structure is shown in Figure 2. An intramolecular $\mathrm{O}_{2}-\mathrm{H}_{2} \cdots$ Olhydrogen bond (distance $\mathrm{O} . . . \mathrm{H}=1.806 \AA, \mathrm{O}-\mathrm{H}=0.820 \AA$, bond angle $=146.64^{\circ}$ ) between the hydroxyl group and the $\mathrm{O}$ atom of carbonyl group forms a sixmembered ring in each molecule, which is nearly coplanar with the naphthone ring and the distances from $\mathrm{C} 1$ atom of acetyl group to mean plane of the three six-membered ring is 0.112(3) $\AA$. There are weak intermolecular $\pi-\pi$ stacking interactions between neighbouring aromatic rings (C3-C8) with centroid-to-centroid distances of $3.844(2) \AA$ (Figure 2). Moreover, the packing structure is stabilized by intermolecular $\mathrm{C}-\mathrm{H} \cdots \pi$ stacking interactions.

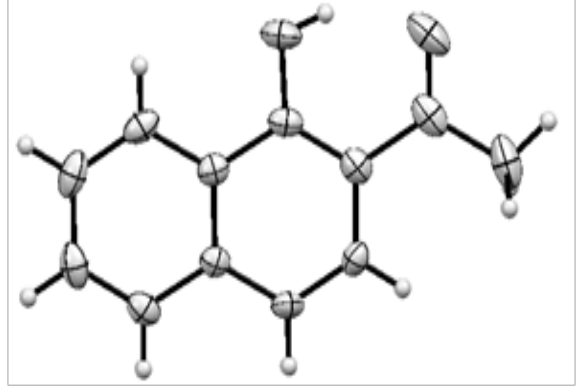

Figure I ORTEP diagram of I-NAPH.

\section{UV-Visible and fluorescence studies}

1-NAPH was screened with a series of metal cations such as $\mathrm{Li}^{+}$, $\mathrm{Na}^{+}, \mathrm{K}^{+}, \mathrm{Eu}^{3+}, \mathrm{Fe}^{2+}, \mathrm{Hg}^{+}, \mathrm{NH}_{4}^{+}, \mathrm{Cu}^{2+}, \mathrm{Cd}^{2+}, \mathrm{Ni}^{2+}, \mathrm{Ba}^{2+}, \mathrm{Mn}^{2+}, \mathrm{Al}^{3+}, \mathrm{Mg}^{2+}$, $\mathrm{Pb}^{2+}, \mathrm{Ca}^{2+}$ and $\mathrm{Zn}^{2+}$ respectively. The UV-visible spectra of 1-NAPH in the presence and absence of metal ions showed two broad bands at 255 and $367 \mathrm{~nm}$ with shoulders around $290-300 \mathrm{~nm}$ was observed (Figure 3A). Upon addition of $\mathrm{Cu}^{2+}$ ion, the shoulders around 290300 got disappeared and a hypochromic shift was observed at $255 \mathrm{~nm}$ in the blue shift region. This clearly demonstrates that 1-NAPH was strongly bound to $\mathrm{Cu}^{2+}$ ions. Figure $3 \mathrm{~B}$ shows the fluorescence spectra of 1-NAPH with various metal ions in methanol-water medium.1NAPH showed a strong fluorescence at $496 \mathrm{~nm}$ in the presence and absence of various metal ions, when excited at $367 \mathrm{~nm}$. In contrast, the fluorescence of 1-NAPH was almost quenched after addition of $20 \mu \mathrm{mol} / \mathrm{L} \mathrm{Cu}^{2+}$ ions.

The highly sensitive nature of 1-NAPH towards $\mathrm{Cu}^{2+}$ ion was shown in Figure 4A \& 4B. A decrease in absorbance was observed with increasing concentration of $\mathrm{Cu}^{2+}$ ions. In fluorescence emission spectrum, 1-NAPH exhibited a strong fluorescence at $496 \mathrm{~nm}$. Upon gradual addition of increasing amounts of aqueous $\mathrm{Cu}^{2+}$ ion solution, the fluorescence emission at 496 was quenched. This showed the strong interaction between 1-NAPH and $\mathrm{Cu}^{2+}$ ions.

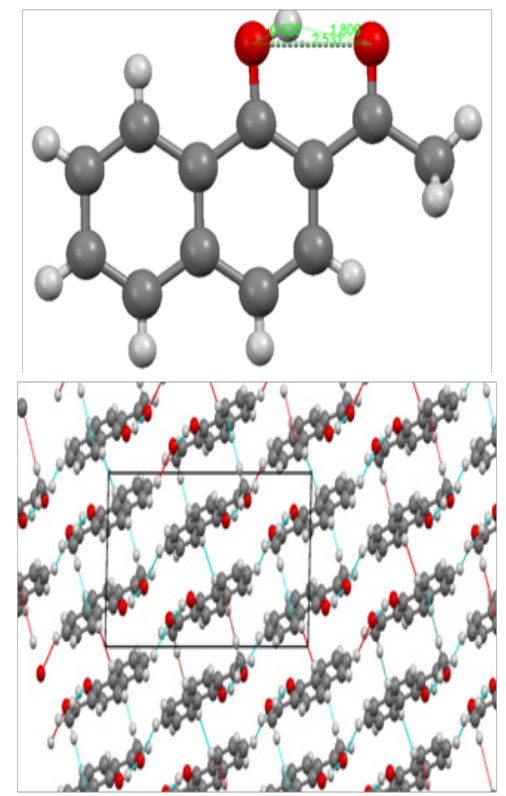

Figure $2 \mathrm{X}$-ray structure of I-NAPH showing intramolecular $\mathrm{H}$-bonding and packing.
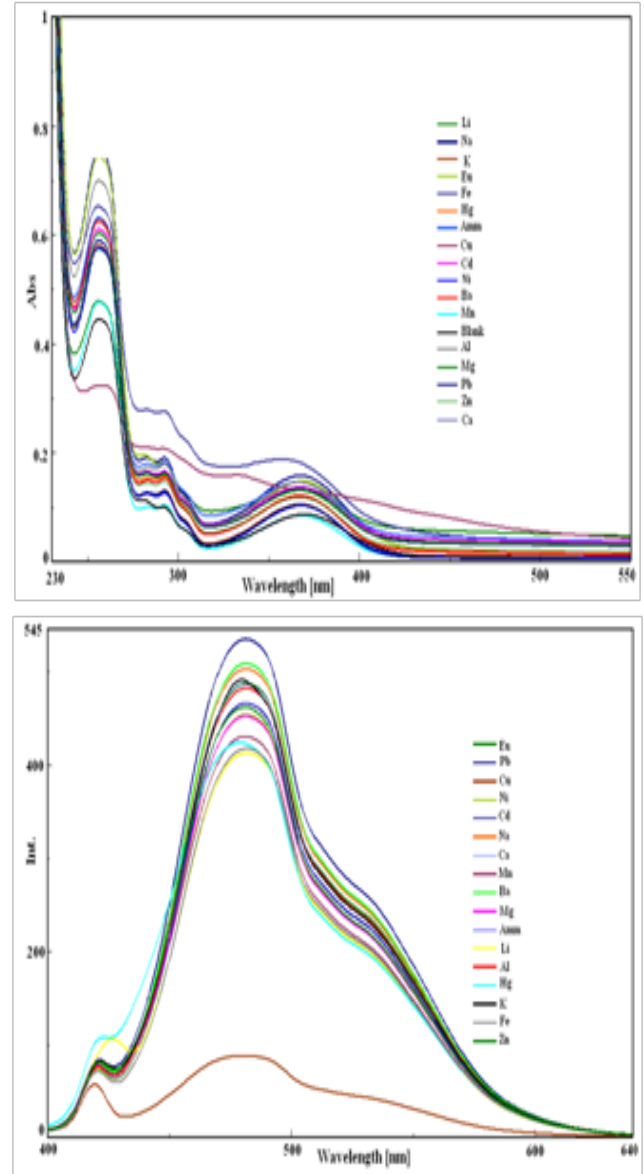

Figure 3 Changes in the (a) absorption spectra and (b) fluorescence spectra of I-NAPH in the presence of various metal ions. 

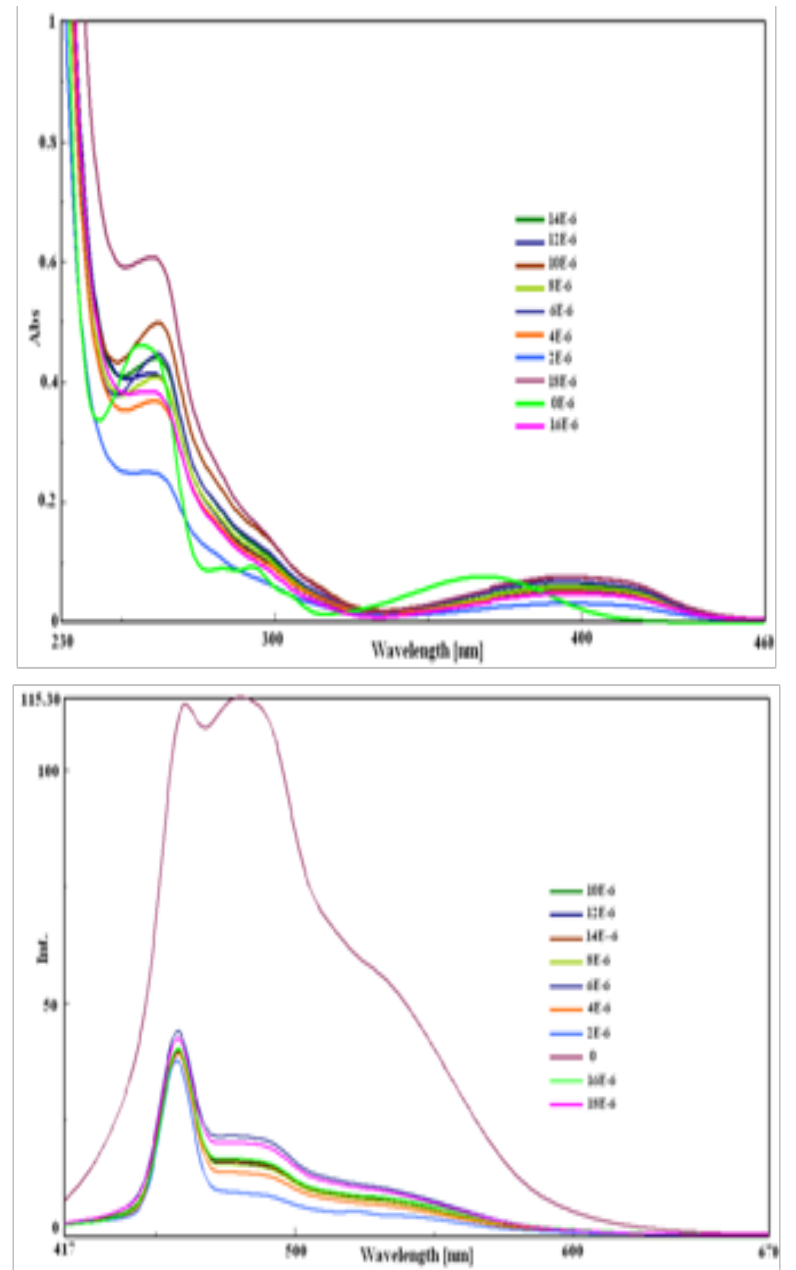

Figure 4 Changes in (a) Absorption and (b) emission spectra of I-NAPH upon gradual addition of $\mathrm{Cu}^{2+}$ ions.

\section{Solvent effect}

Absorbance and fluorescence emission spectra (Figure 5A \& 5B) of 1-NAPH were recorded in different solvents viz., ethanol, dimethyl sulfoxide, dimethyl formamide, chloroform and acetonitrile of total concentration $10 \mu \mathrm{M}$. UV spectrum of 1-NAPH with various solvents shows increase in polarity of solvents lead to hyperchromic shift of the absorption bands for the corresponding solvents. Emission spectra showed that maximum fluorescence intensity was observed for DMF.

\section{pH effect}

The effect of $\mathrm{pH}$ of the solution, in which the sensor is applied, is a critical factor that must be considered definitely. The study of effect of $\mathrm{pH}$ of 1-NAPH towards $\mathrm{Cu}^{2+}$ ion was investigated from $\mathrm{pH}$ range 2.0-12.0. As shown in the Figure 6, UV-Visible spectra showed gradual decrease in absorbance with increasing $\mathrm{pH}$. Under neutral $\mathrm{pH}$, the absorbance of 1-NAPH was quenched maximally. Evidently, the binding between hydroxyl group and $\mathrm{Cu}^{2+}$ caused this pronounced decrease, which also demonstrated the recognition ability of hydroxyl group toward $\mathrm{Cu}^{2+}$. In acidic $\mathrm{pH}$ range, the hydroxyl group of 1-NAPH was protonated and so decreases the binding of 1-NAPH with $\mathrm{Cu}^{2+}$ ions. In basic range from $\mathrm{pH} 10-12$, a red shift was observed due to the strong binding between 1-NAPH and $\mathrm{Cu}^{2+}$ ion.
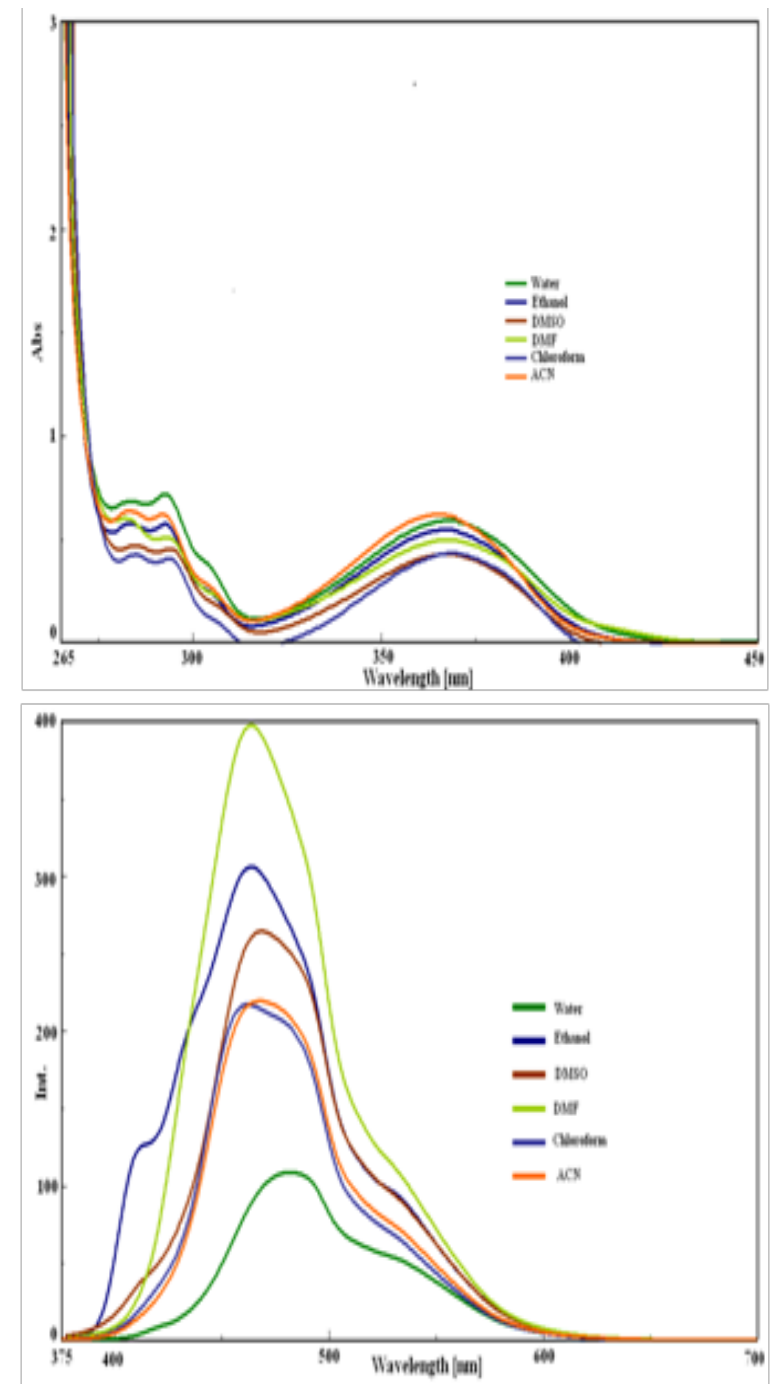

Figure 5 (a) Absorbance and (b) Emission spectra of I-NAPH with various solvents.

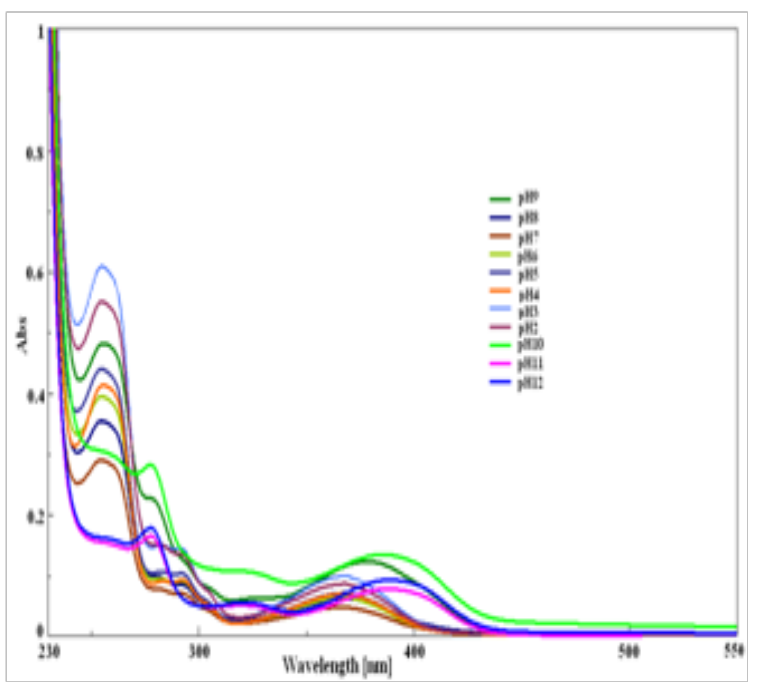

Figure 6 (a) Absorbance and (b) Emission spectra of I-NAPH with various $\mathrm{pH}$. 


\section{Proposed binding mode}

Based on the above studies, we proposed a binding mode between 1-NAPH and $\mathrm{Cu}^{2+}$ ion (Scheme 1). The X-ray crystal study of 1-NAPH confirmed the presence of intramolecular hydrogen bonding between the hydroxyl group and the $\mathrm{O}$ atom of carbonyl group forms a six-membered ring in each molecule. The interaction of $\mathrm{Cu}^{2+}$ with 1-NAPH includes the annihilation of the hydrogen bonding and so $\mathrm{Cu}^{2+}$ ion is bound to the oxygen atom of the hydroxyl and the oxygen atom of the carbonyl group.

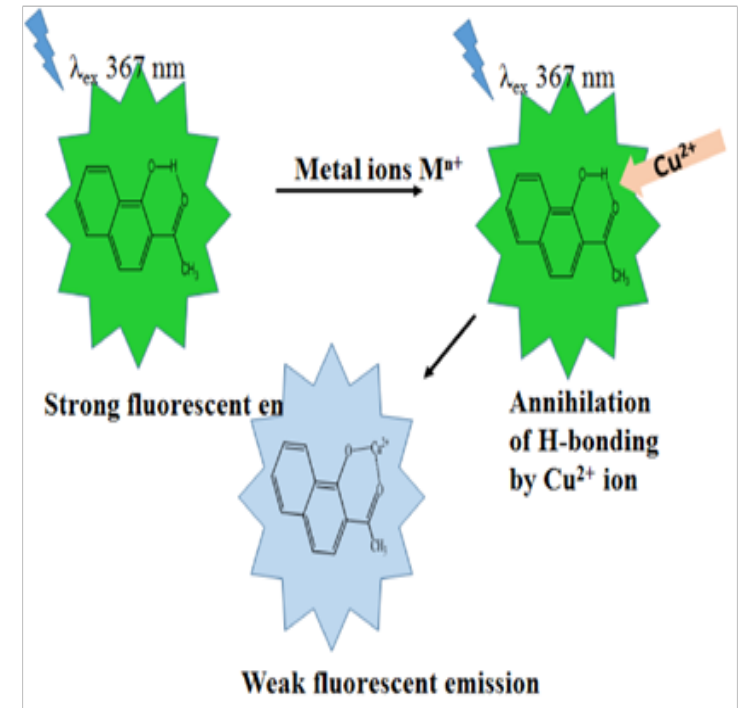

Scheme I Proposed binding mode between I-NAPH and Cu2+ ion.

\section{Conclusion}

Single crystal structure of 1-NAPH was studied by X-ray diffraction method which revealed the existence of intramolecular hydrogen bonding. The structure is stabilized by intramolecular $\mathrm{H}$-bonding and by intermolecular $\mathrm{C}-\mathrm{H} \cdots \pi$ and $\pi-\pi$ stacking interactions. $1-\mathrm{NAPH}$ acts as a selective fluorescent receptor for $\mathrm{Cu}^{2+}$ ions in aqueous medium. The fluorescence emission of 1-NAPH was quenched in the presence of $\mathrm{Cu}^{2+}$ ions upon excitation at $367 \mathrm{~nm}$. When titrated with various metal ions, the fluorescence emission of 1-NAPH was quenched in the presence of $\mathrm{Cu}^{2+}$ ion. We conclude that 1-NAPH acts as on-offon molecular switch towards $\mathrm{Cu}^{2+}$ ions due to its fluorescence Turn "OFF" behavior.

\section{Acknowledgements}

P.M.S.K. is thankful to the Science and Engineering Research Board (SERB), Department of Science and Technology, India, for the financial support (Project number SR/FT/CS-068/2012).

\section{Conflict of interest}

The author declares no conflict of interest.

\section{References}

1. Krämer R. Fluorescent Chemosensors for $\mathrm{Cu}^{2+}$ Ions: Fast, Selective, and Highly Sensitive. Angew Chem Int. 1998;37(6):772-773.

2. Barnham KJ, Masters CL, Bush AL. Neurodegenerative diseases and oxidative stress. Nat Rev Drug Discov. 2004;3(3):205-214.
3. Deraeve C, Boldron C, Maraval A, et al. Preparation and Study of New Poly-8-Hydroxyquinoline Chelators for an anti-Alzheimer Strategy. Chemistry. 2008;14(2):682-696.

4. Lee YF, Deng TW, Chiu WJ, et al. Visual detection of copper (II) ions in blood samples by controlling the leaching of protein-capped gold nanoparticles. Analyst. 2012;137(8):1800-1806.

5. Ye S, Shi X, Gu W, et al. A colorimetric sensor based on catechol-terminated mixed self-assembled monolayers modified gold nanoparticles for ultrasensitive detections of copper ions. Analyst. 2012;137(14):33653371.

6. Hua C, Zhang WH, De Almeida SR, et al. A novel route to copper (II) detection using 'click' chemistry-induced aggregation of gold nanoparticles. Analyst. 2012;137(1):82-86.

7. Wang Q, Tan C. Terbium hybrid particles with spherical shape as luminescent probe for detection of $\mathrm{Cu} 2+$ and $\mathrm{Fe} 3+$ in water. Anal Chim Acta. 2011;708(1-2):111-115.

8. Liu J, Lu Y. A DNAzyme Catalytic Beacon Sensor for Paramagnetic $\mathrm{Cu}^{2+}$ Ions in Aqueous Solution with High Sensitivity and Selectivity. $J$ Am Chem Soc. 2007;129(32):9838-9839.

9. Turel M, Duerkop A, Yegorovab A, et al. Detection of nanomolar concentrations of copper (II) with a $\mathrm{Tb}$-quinoline-2-one probe using luminescence quenching or luminescence decay time. Anal Chim Acta. 2009;644(1-2):53-60.

10. Sumathi P, Anju Kannan P, Sivaraj R, et al. A simply synthesized biphenyl substituted piperidin-4-one for the fluorescence chemosensing of $\mathrm{Cd}^{2+}$. Luminescence. 2017;32(8):1405-1410.

11. Sumithra M, Sivaraj R, Selvan GT, et al. $\mathrm{Ca}^{2+}$ ion sensing by a piperidin-4-one derivative and the effect of $\beta$-cyclodextrin complexation on the sensing. Journal of Luminescence. 2017;185:205-211.

12. Paulpandi RQ, Sivaraj R, Mosae SP, et al. Enhanced $\mathrm{Zn}^{2+}$ ion-sensing behavior of a benzothiazole derivative on encapsulation by $\beta$-cyclodextrin. $R S C A d v .2016 ; 19(6): 15670-15677$.

13. Antony EJ, Raj M, Rajathi QP, et al. A highly selective fluorescent sensor for $\mathrm{Pb}^{2+}$ based on a modified $\beta$-cyclodextrin. Journal of Fluorescence. $2015 ; 25(4): 1031-1036$.

14. N Mergu, VK Gupta. A novel colorimetric detection probe for copper (II) ions based on a Schiff base. Sens Actuators B Chem. 2015;210:408-417.

15. Shiraishi Y, Tokitoh Y, Nishimura G, et al. A Molecular Switch with $\mathrm{pH}-$ Controlled Absolutely Switchable Dual-Mode Fluorescence. Org Lett. 2005;7(13):2611-2614.

16. Yousuf S, Alex R, Paulraj MS, et al. Picking Out Logic Operations in a Naphthalene $\beta$-Diketone Derivative by Using Molecular Encapsulation, Controlled Protonation, and DNA Binding. Chemistry Open. 2015;4(4):497-508.

17. Tamilselvan G, Kumaresan M, Sivaraj R, et al. Isomeric 4-aminoantipyrine derivatives as fluorescent chemosensors of $\mathrm{Al}^{3+}$ ions and their molecular logic behavior. Sens and Actuators B Chem. 2016;229:181-189.

18. SADABS, Empirical absorption Correction Program; University of Göttingen: Göttingen, Germany, 1997.

19. Sheldrick GM. SHELXTL Reference manual. Version 5.1; WI: Bruker AXS; 1997.

20. Sheldrick GM, SHELXL-97: Program for Crystal Structure Refinement; University of Göttingen: Göttingen, Germany, 1997.

21. Spek AL. PLATON-97. Netherlands: University of Utrecht; 1997.

22. Mercury 1.3 Supplied with Cambridge Structural Database. UK: CCDC; 2004. 